\title{
Damping Procedure for Mixed Control with Variable Coefficients of the Neighborhood Model
}

\author{
A.M. Shmyrin ${ }^{* 1}$, A.G. Yartsev ${ }^{* 2}$ \\ *Lipetsk State Technical University, Russia \\ ORCID: ${ }^{1}$ O000-0001-8454-6032, ${ }^{2} 0000-0002-9288-0089$
}

\begin{abstract}
In the article, a bilinear neighborhood model of an installation for maintaining the optimum temperature of the polyol is considered. To determine the heat transfer coefficient, traditional mixed control and mixed control with variable coefficients were carried out. To improve the mixed control procedure with variable coefficients, damping is applied - imposing restrictions on the possible variation of the values of the variable coefficients. A comparison of the results of mixed controls with the results of determining the heat transfer coefficient with the help of thermotechnical calculation is made. The values of the deviations of the neighborhood model are presented for different variants of mixed control.
\end{abstract}

Keywords:

\section{Introduction}

Polyol is one of the components in the production of polyurethane foams. In production, its temperature should be maintained above $22{ }^{\circ} \mathrm{C}$, since otherwise it hardens. To maintain the optimum temperature of the polyol in the production, special installations with a heat exchanger are used.

In the production process, it is important to accurately and timely determine the heat transfer coefficient of the heat exchanger. In engineering practice, for this purpose a thermotechnical calculation is carried out, which is an accurate but rather laborious method, since it includes a large number of formulas and criteria equations.

The use of neighborhood systems for modeling and controlling installations of this kind is a promising direction, since with the help of mixed control it is possible to speed up and simplify the process of determining the heat transfer coefficient.

The theory of neighborhood systems is a universal tool for modeling a class of discrete distributed systems [1]. Neighborhood models develop general approaches to the theory of systems, control theory and generalize such traditional discrete models as finite and cellular automata, Petri nets, difference equations, etc. The use of the neighborhood approach in applied problems covers systems of different nature and orientation - from technical to economic ones. The aim of this paper is to determine the heat transfer coefficient of the heat exchanger using mixed control of the neighborhood model, the application of the damping procedure for mixed control with variable coefficients, the comparison of the results of determining the heat transfer coefficient in the mixed control processes and the thermotechnical calculation, comparing the mean square deviations of the neighborhood model with different variants of mixed control.

\section{Research Method}

The neighborhood model of the installation for maintaining the optimum temperature of the the polyol consists of five nodes [2]: 1 - polyol storage container, 2 - polyol transfer pump, 3 - heat exchanger, 4 - polyol consumer, 5 - a refrigerator.

To construct a neighborhood model, it is necessary to carry out identification, for which it is necessary to know the essential components of state and control and their nominal values, which are presented in Table 1.

Table 1. Components of state and control and their nominal values

\begin{tabular}{|c|c|c|}
\hline $\mathrm{x}[1]$ & Polyol temperature in the storage container, ${ }^{\circ} \mathrm{C}$ & $40{ }^{\circ} \mathrm{C}$ \\
\hline $\mathrm{x}[2]$ & Polyol consumption, tons/day & $\begin{array}{c}13,2 \\
\text { tons/day }\end{array}$ \\
\hline $\mathrm{x}[3]$ & $\begin{array}{c}\text { Heat transfer coefficient of the heat exchanger, } \\
\mathrm{W} /\left(\mathrm{m}^{2} \cdot \mathrm{K}\right)\end{array}$ & $\begin{array}{c}71,2 \\
\mathrm{~W} /\left(\mathrm{m}^{2} \cdot \mathrm{K}\right)\end{array}$ \\
\hline $\mathrm{x}[4]$ & $\begin{array}{c}\text { Temperature of polyol transferred to the consum- } \\
\mathrm{er},{ }^{\circ} \mathrm{C}\end{array}$ & $2{ }^{\circ} \mathrm{C}$ \\
\hline $\mathrm{x}[5]$ & $\begin{array}{c}\text { Temperature difference of the heating agent before } \\
\text { and after the heat exchanger, }{ }^{\circ} \mathrm{C}\end{array}$ & $5^{\circ} \mathrm{C}$ \\
\hline $\mathrm{v}[1]$ & Polyol reserve in the storage container, tons & 22 tons \\
\hline $\mathrm{v}[2]$ & Rotation speed of the pump shaft, rpm & $319 \mathrm{rpm}$ \\
\hline $\mathrm{v}[3]$ & Polyol temperature after the heat exchanger, ${ }^{\circ} \mathrm{C}$ & $22{ }^{\circ} \mathrm{C}$ \\
\hline $\mathrm{v}[4]$ & $\begin{array}{c}\text { Consumption of polyol transferred to the consum- } \\
\mathrm{er}, \text { tons/day }\end{array}$ & $\begin{array}{c}11,9 \\
\text { tons/day }\end{array}$ \\
\hline $\mathrm{v}[5]$ & Heating agent consumption, tons/day & $\begin{array}{c}27,5 \\
\text { tons/day }\end{array}$ \\
\hline
\end{tabular}

To carry out identification, it is required to specify a part of the coefficients of the model, for which the formulas were applied, in which the normalized values of the parameters were substituted [2]: 
$w_{x}[i, j]=\frac{x[j]}{\sum_{j=1}^{n} x[j]}, w_{v}[i, k]=\frac{v[k]}{\sum_{k=1}^{n} v[k]}$.

According to the formulas, the following values were obtained: $\mathrm{w}_{\mathrm{x}}[1,1]=-1,32065$ $\mathrm{w}_{\mathrm{v}}[1,1]=-0,325$

$\mathrm{w}_{\mathrm{x}}[2,2]=-0,50894$

$\mathrm{w}_{\mathrm{x}}[3,3]=-4,20988$

$\mathrm{w}_{\mathrm{x}}[4,4]=-0,25368$

$\mathrm{w}_{\mathrm{x}}[5,5]=-1,61637$;

$\mathrm{W}_{\mathrm{v}}[2,2]=1,96296$

$\mathrm{W}_{\mathrm{v}}[3,3]=-1$

$\mathrm{w}_{\mathrm{v}}[4,4]=0,53937$

$\mathrm{w}_{\mathrm{V}}[5,5]=0,47534$

The bilinear neighborhood model of an installation for maintaining the optimum temperature of the polyol and the values of the coefficients obtained as a result of identification are presented in [2].

With mixed control, a part of the state and control parameters is specified, and the remaining parameters must be determined based on the minimum condition for the mean square deviation of the neighborhood model from zero [3]

$$
\sqrt{\frac{\sum_{\mathrm{i}=1}^{\mathrm{n}}\left(\mathrm{F}_{\mathrm{i}}\right)^{2}}{\mathrm{n}}} \rightarrow \min ,
$$

where $F_{i}$ - equation for the $i$-th node of the system, $n$ - number of equations corresponding to the number of nodes in the system Two mixed controls were performed: traditional mixed control, in which the coefficients of the model are unchanged and mixed control with variable coefficients, at which part of the coefficients determined by formulas (1) can change their value [4]

\section{Results and Analysis}

The results of determining the heat transfer coefficient, with varying values of the polyol consumption $\mathrm{x}[2]$ and the temperature difference of the heating agent before and after the heat exchanger x[5], are shown in Fig. 1 and Fig. 2.

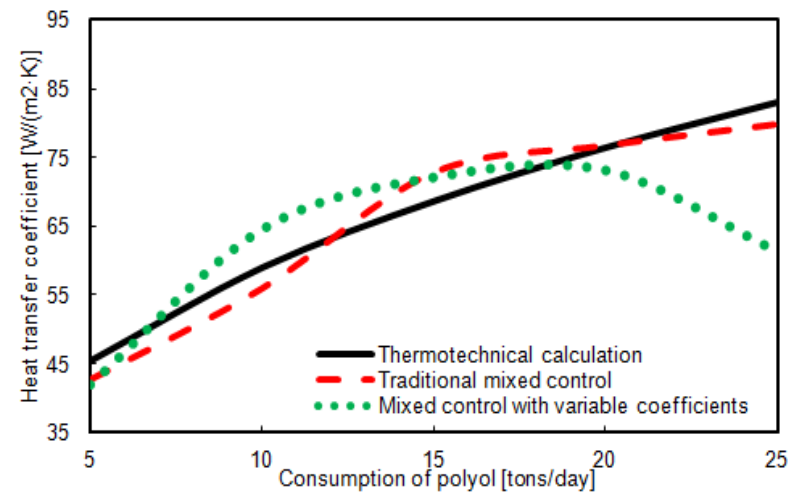

Fig. 1. The values of the heat transfer coefficient at the value of the temperature difference of the heating agent $x[5]=10^{\circ} \mathrm{C}$

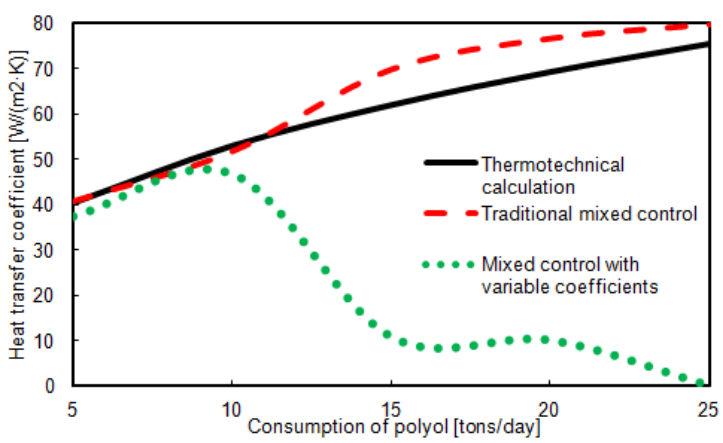

Fig. 2. The values of the heat transfer coefficient at the value of the temperature difference of the heating agent $x[5]=20^{\circ} \mathrm{C}$
When using mixed control with variable coefficients, errors increase, which is explained by the expansion of the range of values of parameters and coefficients. This is noticeable when removing the temperature difference of the heating agent $\mathrm{x}[5]$ from the nominal value, as a result of which the mixed control produces a zero value of the heat transfer coefficient (Fig. 2).

To eliminate this disadvantage, we apply the damping procedure imposing restrictions on the possible variation in the values of the coefficients, which can change in the process of mixed control with variable coefficients.

Three damping procedures were carried out, where the variable coefficients can take values in the range $\pm 90 \%, \pm 50 \%$ and $\pm 10 \%$ of the nominal value.

The results of mixed control with variable coefficients with damping are shown in Fig. 3 and Fig. 4.

Relative deviations of the values of the heat transfer coefficient found in the process of different variants of mixed control from the values obtained as a result of thermotechnical calculation are presented in Table 2 .

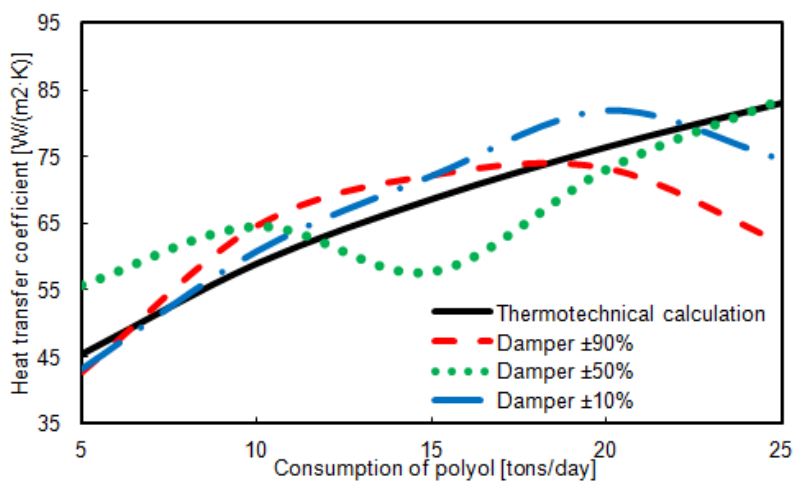

Fig. 3. The values of the heat transfer coefficient as a result of mixed control with damping at the value of the temperature difference of the heating agent $x[5]=10^{\circ} \mathrm{C}$

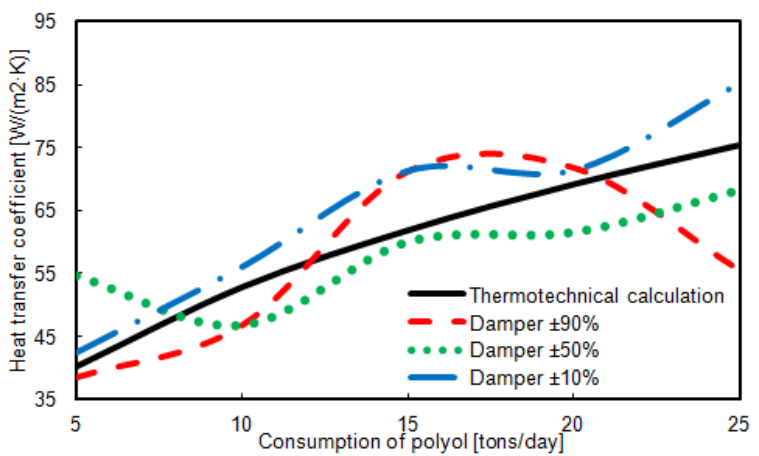

Fig. 4. The values of the heat transfer coefficient as a result of mixed control with damping at the value of the temperature difference of the heating agent $x[5]=20^{\circ} \mathrm{C}$

Table 2. Values of relative deviations, $\%$

\begin{tabular}{|c|c|c|c|c|c|c|}
\hline \multicolumn{2}{|c|}{ Set value } & \multicolumn{5}{|c|}{ Mixed control } \\
\hline $\begin{array}{c}\mathrm{x}[2], \\
\text { tons/da } \\
\mathrm{y}\end{array}$ & $\begin{array}{c}\mathrm{x}[5] \\
{ }^{\circ} \mathrm{C}\end{array}$ & $\begin{array}{c}\text { tradition- } \\
\text { al }\end{array}$ & $\begin{array}{c}\text { with vari- } \\
\text { able } \\
\text { coeffi- } \\
\text { cients }\end{array}$ & $\begin{array}{c}\text { damp- } \\
\text { er } \\
\pm 90 \%\end{array}$ & $\begin{array}{c}\text { damp- } \\
\text { er } \\
\pm 50 \%\end{array}$ & $\begin{array}{c}\text { damp- } \\
\text { er } \\
\pm 10 \%\end{array}$ \\
\hline 5 & 10 & -5.95 & -7.71 & -6.17 & 22.91 & -5.07 \\
\hline 10 & 10 & -5.08 & 9.49 & 9.49 & 9.49 & 3.05 \\
\hline 15 & 10 & 6.11 & 5.09 & 5.09 & -15.87 & 4.95 \\
\hline 20 & 10 & 0.39 & -4.31 & -4.31 & -4.31 & 7.06 \\
\hline 25 & 10 & -3.85 & -26.23 & -25.39 & 0.6 & -10.35 \\
\hline 5 & 20 & 1.49 & -6.95 & -4.22 & 35.48 & 5.46 \\
\hline 10 & 20 & -1.89 & -11.34 & -11.34 & -11.53 & 6.05 \\
\hline 15 & 20 & 13.09 & -82.55 & 15.19 & -3.07 & 15.19 \\
\hline 20 & 20 & 10.98 & -85.4 & 3.76 & -11.13 & 3.18 \\
\hline 25 & 20 & 5.97 & -100 & -26.39 & -9.55 & 13 \\
\hline
\end{tabular}

The values of the heat transfer coefficient, determined as a result of the traditional mixed control and mixed control with variable coefficients with a damping of $\pm 10 \%$, do not exceed the permissi- 
ble error of $15 \%$, which the criteria equations for determining the heat transfer coefficient have [5]. This fact indicates the possibility of using neighborhood systems for modeling and controlling heat exchangers.

An important parameter of the neighborhood model is its accuracy. A smaller value of the deviation of the system from zero indicates greater stability of the system [6]. The values of the mean square deviations of the system are shown in Table 3 .

Table 3. Values of mean square deviations

\begin{tabular}{|c|c|c|c|c|c|c|}
\hline \multicolumn{2}{|c|}{ Set value } & \multicolumn{5}{c|}{ Mixed control } \\
\hline $\begin{array}{c}\mathrm{x}[2], \\
\text { tons/da } \\
\mathrm{y}\end{array}$ & $\begin{array}{c}\mathrm{x}[5] \\
{ }^{\circ} \mathrm{C}\end{array}$ & $\begin{array}{c}\text { tradi- } \\
\text { tional }\end{array}$ & $\begin{array}{c}\text { with vari- } \\
\text { able } \\
\text { coeffi- } \\
\text { cients }\end{array}$ & $\begin{array}{c}\text { damper } \\
\pm 90 \%\end{array}$ & $\begin{array}{c}\text { damper } \\
\pm 50 \%\end{array}$ & $\begin{array}{c}\text { damper } \\
\pm 10 \%\end{array}$ \\
\hline 5 & 10 & 0.26477 & 0.00903 & $\begin{array}{c}0.0031 \\
5\end{array}$ & $\begin{array}{c}0.0612 \\
2\end{array}$ & $\begin{array}{c}0.2253 \\
5\end{array}$ \\
\hline 10 & 10 & 0.19382 & 0.02694 & $\begin{array}{c}0.0269 \\
4\end{array}$ & $\begin{array}{c}0.0269 \\
4\end{array}$ & $\begin{array}{c}0.0573 \\
7\end{array}$ \\
\hline 15 & 10 & 0.19507 & 0.09447 & $\begin{array}{c}0.0944 \\
7\end{array}$ & $\begin{array}{c}0.0370 \\
1\end{array}$ & $\begin{array}{c}0.0929 \\
7\end{array}$ \\
\hline 20 & 10 & 0.66179 & 0.08998 & $\begin{array}{c}0.0899 \\
8\end{array}$ & $\begin{array}{c}0.0911 \\
1\end{array}$ & $\begin{array}{c}0.4047 \\
2\end{array}$ \\
\hline 25 & 10 & 1.14159 & 0.077 & $\begin{array}{c}0.0745 \\
5\end{array}$ & $\begin{array}{c}0.1043 \\
6\end{array}$ & $\begin{array}{c}0.9082 \\
3\end{array}$ \\
\hline 5 & 20 & 0.20926 & 0.02579 & $\begin{array}{c}0.0133 \\
5\end{array}$ & $\begin{array}{c}0.0298 \\
2\end{array}$ & $\begin{array}{c}0.1689 \\
8\end{array}$ \\
\hline 10 & 20 & 0.33537 & 0.03142 & $\begin{array}{c}0.0314 \\
2\end{array}$ & $\begin{array}{c}0.0258 \\
3\end{array}$ & $\begin{array}{c}0.2175 \\
9\end{array}$ \\
\hline 15 & 20 & 0.27709 & 0.09384 & $\begin{array}{c}0.2278 \\
1\end{array}$ & $\begin{array}{c}0.1420 \\
4\end{array}$ & $\begin{array}{c}0.2278 \\
1\end{array}$ \\
\hline 20 & 20 & 0.62237 & 0.11376 & $\begin{array}{c}0.2353 \\
8\end{array}$ & $\begin{array}{c}0.1554 \\
1\end{array}$ & $\begin{array}{c}0.4680 \\
5\end{array}$ \\
\hline 25 & 20 & 1.06536 & 0.0278 & $\begin{array}{c}0.1207 \\
7\end{array}$ & $\begin{array}{c}0.3199 \\
8\end{array}$ & $\begin{array}{c}0.8404 \\
3\end{array}$ \\
\hline
\end{tabular}

The advantage of mixed control with variable coefficients is a much smaller deviation of the left side of the equations of the system from zero. But this improvement is offset by an increase in errors in the system, due to the lack of restrictions on the coefficients of the model. The application of damping slightly increases the mean square deviation of the system, which is still lower than in the traditional mixed control, but significantly improves the results of mixed control.

\section{Conclusion}

In this paper, the traditional mixed control and mixed control with variable coefficients were carried out to determine the heat transfer coefficient of the heat exchanger of an installation for maintaining the optimum temperature of the polyol.

Mixed control with variable coefficients showed a significantly lower deviation of the system from zero, compared with traditional mixed control, but poor results were obtained with respect to the determination of the heat transfer coefficient. Damping was used to correct this situation.

The damping procedure - imposing restrictions on the possible variation of the values of the variable coefficients - should be applied if the system parameters are very different from the nominal values. At the same time, the more parameters deviate from the nominal mode, the more rigid damping should be used.

The obtained values of the heat transfer coefficient, found in the process of traditional mixed control and mixed control with variable coefficients with damping $\pm 10 \%$, correspond to the values obtained in the thermotechnical calculation, which indicates the possibility of using neighborhood systems to control installations of this kind.

\section{Acknowledgements}

The reported study was funded by RFBR according to the research project № 16-07-00854 a.

\section{References}

[1] Blyumin, S.L, (2006), Bilinear neighborhood systems / S.L. Blumin, A.M. Shmyrin, O.A. Shmyrina. - Lipetsk: LSTU, p. 131

[2] Shmyrin, A. M, (2018), Algorithms of identification of neighborhood systems by the example of simulation of an installation for maintaining the optimum temperature of the polyol, A. M. Shmyrin, A. G. Yartsev, Modern informatization problems in the techoligical and telecommunication systems analysis and synthesis: Proceedings of the XXIII-th International Open Science Conference (Yelm, WA, USA, January 2018). - Science Book Publishing House, p. 277-286. Shmyrin, A.M, (2015), Study of the neighborhood models of the clinker kiln taking into account restrictions on variables and a special objective function, A.M. Shmyrin, A.G. Yartsev, Information Technologies of Modeling and Control, No. 5 (95), p. 410-418. Shmyrin, A.M, (2017), Application of mixed control for determining the heat transfer coefficient of a heat exchanger, A.M. Shmyrin, A.G. Yartsev, International journal of Applied engineering research, Vol. 12, No. 20, p. 10399-10401

[5] Romankov, P.G, (1982), Heat transfer processes of chemical technology, P.G. Romankov, V.F. Frolov - L.: Chemistry, p. 288. Shmyrin, A.M, (2016), Mixed control of formation process temperature coiling hot rolled strips based on trilinear neighborhood model, A. M. Shmyrin, A.G. Yartsev, Information Technology of Modeling and Control, No. 4(100), pp. 290-297. 